\title{
Core aspects of ubuntu: A systematic review
}

\author{
C Ewuoso, PhD; S Hall, PhD \\ Centre for Applied Ethics, Department of Philosophy, Faculty of Arts and Social Sciences, Stellenbosch University, Cape Town, South Africa
}

Corresponding author: C Ewuoso (corneliusewuoso@bioethicscenter.net)

\begin{abstract}
Background. Ubuntu has been proposed as a useful alternative to current (Western) ethical frameworks for evaluating global bioethical issues, contributing theoretical diversity to the clinical context. However, the literature regarding this philosophy is often described as confusing, and is characterised by a number of competing interpretations.

Objective. To arrive, by way of a systematic review, at a definition of ubuntu that encompasses the common themes that appear in competing interpretations.

Methods. Searches were done in PhilPaper, PubMed and Google Scholar using a variety of search strings, generating 1207 hits. After screening for English language, as well as relevance of the article after reading the title, abstract and full text, 99 articles were included for review. Another 17 articles were identified through snowballing and additional searches, giving a total of 116 articles that were included in the review.

Results. This review shows that ubuntu is an essentially relational ethics, which prizes relationships of interdependence, fellowship, reconciliation, relationality, community friendliness, harmonious relationships and other-regarding actions such as compassion and actions that are likely to be good for others, in which actions are morally right to the extent that they honour the capacity to relate communally, reduce discord or promote friendly relationships with others, and in which the physical world and the spiritual world are fundamentally united.

Conclusion. Scholars, health professionals, policy makers and others should be aware that an alternative ethical theory exists in the global South that may be applied to address a variety of global (bio)ethical issues. Further research, however, is needed to evaluate how properly action-guiding this formulation is in particular contexts.
\end{abstract}

SAfr J Bioethics Law 2019;12(2):93-103. https://doi.org/10.7196/SAJBL.2019.v12i2.679

Ubuntu has been proposed as a useful alternative to current (Western) ethical frameworks for evaluating global bioethical issues ${ }^{[1-5]}$ and contributing theoretical diversity to the clinical context. ${ }^{[6-8]}$ Ubuntu, Komparic ${ }^{[3]}$ and others such as Cilliers ${ }^{[9]}$ contend, is an African moral system that has been influential across a wide geographical area, and over a long timespan, south of the Sahara. This philosophy has its origins in the pre-colonial era, but has risen to prominence in the philosophical literature in post-apartheid South Africa (SA). Ubuntu is principally a normative ethical system among the people of southern Africa. ${ }^{[10,11]}$ It must also be emphasised, however, that ubuntu should not necessarily be taken to be representative of all ethical thinking in Africa. ${ }^{[12]}$ In addition, the question as to how widely held this theory is in practice is researchable, but outside the scope of this study. Metz, ${ }^{[4,13]}$ for example, has observed that his particular philosophical construction of ubuntu is not necessarily widely believed or applied. Ubuntu nonetheless encompasses a range of salient behaviours, ways of thinking and favoured norms, which are not necessarily unique to Africa, but neither have these behaviours and ways of thinking come to it from other continents. ${ }^{[14-21]}$

Recently, a flurry of writings have emerged regarding this ethical theory, which some scholars such as Matolino ${ }^{[22]}$ have described as largely confusing and as containing competing interpretations of ubuntu. For this reason, it can be challenging to understand this ethical theory, or to identify specific moral rules for ethical decisionmaking that may arise from it. The goal of the present study is therefore descriptive: firstly, to contribute towards a definition of ubuntu that encompasses the common themes that appear in existing, and sometimes competing, interpretations, and secondly, to highlight specific moral rules for ethical decision-making that arise from this theory in the context of clinical care and bioethics more globally.

The study is neither an attempt to reinvent ubuntu nor an attempt to rescue it from its critics. Rather, it will carefully organise existing thoughts on the nature of ubuntu in order to answer the stated research question via the methodology of a systematic review. We are not aware of any study that has directly considered the research objectives defined in this way, although some studies ${ }^{[23-28]}$ have offered a narrative literature review of existing writings on ubuntu. In the next few paragraphs, we shall motivate the use of a systematic, rather than narrative, review for the descriptive aim of this study.

Narrative literature reviews and systematic literature reviews are differentiated by the methodology they employ for the selection of reviewed studies. A narrative review qualitatively summarises evidence on a topic using informal or subjective methods to select studies. In a narrative review, the selection process may be arbitrary: the reasons for preferring one study to another are usually not stated. Other information such as the method used for searching relevant materials, searched database(s), the material selection process, search strings and so on are often not provided in such studies. All of this can potentially increase study bias as the researcher may, for example, be more inclined to include texts with which they are most familiar, or that confirm their own views.

Systematic reviews, on the other hand, are regarded as a thorough, less biased and more objective methodology for answering descriptive questions, ${ }^{[29-33]}$ such as the one posed in this study. A 
systematic review is a complex, high-level overview of primary research, which sets out to answer well-defined and focused questions by systematically identifying, choosing, synthesising and assessing all relevant high-quality primary studies with pre-specified and explicit eligibility criteria. This methodology ensures that the article selection process is transparent and can be replicated. In other words, a systematic literature review ensures that all relevant studies that ought to be included for review are not excluded without justification, thus minimising the risk of human bias.

Moreover, using a systematic literature review to answer a research question in philosophical ethics is not entirely new. ${ }^{[34,35]}$ Mertz et al. ${ }^{[36]}$ note that systematic reviews of ethics literature exist (for example, Parris and Peachey ${ }^{[33]}$ used systematic reviews to empirically examine how the construct 'servant leadership' is morally defined in published ethical literature, and applied to organisational settings) and also encourage such use - specifically for contributing normative inputs for evidencebased ethical decision-making in clinical care. Decision-making within the clinical context, they contend, is strongly based on external knowledge, such as knowledge of moral philosophy and applied ethics. Non-systematic recovery of such external knowledge risks bias. Non-systematic reviews could also diminish the quality and application of such external knowledge to ethical decision-making. Pae ${ }^{[37]}$ and other ${ }^{[35,36]}$ add that literature reviews such as narrative reviews and eminence-based reviews, which fail to include pre-specified eligibility criteria, can result in methodological shortcomings, leading to bias that may influence an author's interpretation and/or conclusions, ${ }^{37}$ or reducing methodological transparency regardless of the actual methodological quality of a study.

In order to ensure internal validity (to reduce bias and ensure reproducibility) and external validity (for external use), Mertz et $a l^{[35]}$ suggest accurate reporting of selection and analysis criteria, such as in a systematic literature review. The methodological approach of this study fulfils this recommendation, and is therefore likely to identify normative contributions from ubuntu philosophy in a way that is conducive to evidence-based ethical decision-making in bioethics. In summary, a systematic review - rather than a narrative review - is a more suitable approach for the descriptive aim of this study, as it provides a comprehensive overview of the ubuntu literature that minimises selection bias (by pre-specifying inclusion and exclusion criteria). The next section describes the study methodology in more detail.

\section{Methods}

For the purpose of the systematic review, the present study has adapted four steps from the Preferred Reporting Items for Systematic Reviews and Meta-Analysis (PRISMA). ${ }^{[38]}$ These steps are: (i) framing a research question; (ii) a systematic search for relevant materials in relevant databases; (iii) developing pre-specified selection criteria; and (iv) presentation of the results. This is followed by a discussion.

We restate the research question in the following way: is there a theoretical formulation of ubuntu that exists in current literature that is likely to be accepted by most ubuntu scholars as constituting the core aspects of this ethical theory? Using a methodological approach for designing search strings proposed by Pillastrini et $a l^{[39]}$ we developed several search strings to conduct searches in PhilPapers, Google Scholar and PubMed between 21 and 24 July 2017. An additional search was also conducted in the Philosopher's Index and Stellenbosch University online library database to identify relevant articles. The methodological approach developed by Pillastrini et al. ${ }^{[39]}$ generally consists of: framing a research question; looking up MeSH - (Medical) Subject Heading - terms for the components that make up the research question; reading published literature for alternative terms; and finally, combining these MeSH terms with Boolean operators (AND, OR and NOT) in a database to deliver relevant articles. These search strings generated 1207 hits in total. Detailed information regarding the literature search can be found in Table 1.

After screenings for English language (5 articles excluded), as well as relevance of the article after reading the title and abstract (952 articles excluded) and full text (70 articles excluded), and deleting duplicates (86 articles excluded), 99 articles were included for review. Another 14 articles were identified through snowballing; an additional search was also carried out in African Journals Online to identify potential relevant articles. This search generated 11 hits, of which only 1 satisfied the selection criteria. Another 2 articles were identified following system updates in PhilPapers, making a total of 116 articles that were included for review (Fig. 1).

\section{Inclusion and exclusion criteria}

This study seeks to contribute towards a description of ubuntu that encompasses its core aspects or common themes, as identified from existing literature. Hence we have included in this review studies published in English - that attempt to describe the nature, context or features of ubuntu in the ethics literature. Studies that also focus on the ethics of ubuntu with regard to its usefulness and disadvantages were included in the present study, if, and only if, they provide a substantial and original description of ubuntu.

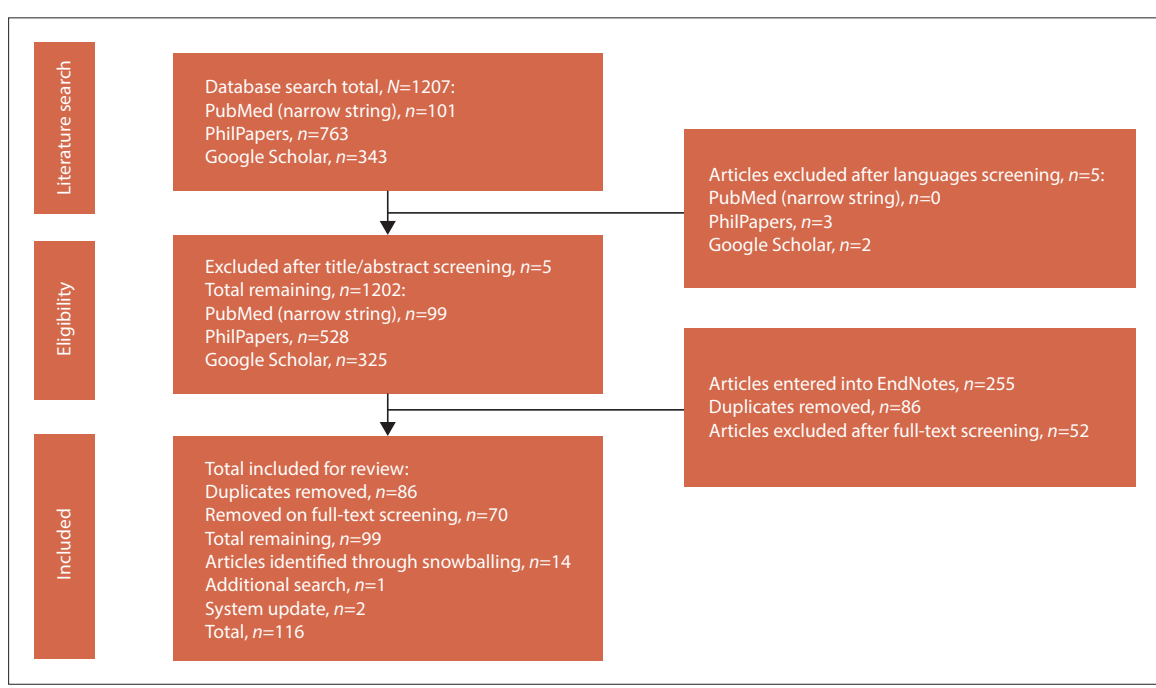

Fig. 1. Article selection process. 
Table 1. Literature search

\begin{tabular}{|c|c|}
\hline Database & Search details \\
\hline PubMed & Search date: 21 July 2017 \\
\hline \multirow[t]{8}{*}{ First search } & Selected restrictions: no restriction \\
\hline & Selected search mode: default mode: sort by relevance \\
\hline & Search string: ((("African Moral Theory" OR "African Ethics" OR "African Ethic" OR "African ethical \\
\hline & theory" OR "African Moral Framework" OR “African philosophy" OR “Philosophy in Africa" OR \\
\hline & "African tradition" OR "Humanistic Ethic" OR "African Morality")) AND (ubuntu OR “Ubuntu- \\
\hline & oriented" OR "Ethics of Ubuntu" OR "African ethic of Ubuntu")) AND (philosophy OR philosophies \\
\hline & OR philosophers OR philosopher) \\
\hline & Hits: 101 \\
\hline PhilPapers & Search date: 23 July 2017 \\
\hline \multirow[t]{7}{*}{ Choose search number: second search } & Selected restrictions: no restriction \\
\hline & Search mode: fuzzy filter (advanced) - more flexible filter \\
\hline & Search string: ((ubuntu OR "Ubuntu-oriented" OR "Ethics of Ubuntu" OR "African ethic of Ubuntu") \\
\hline & AND ("African Moral Theory" OR "African Ethics" OR "African Ethic" OR "African ethical theory" OR \\
\hline & "African Moral Framework" OR "African philosophy" OR "Philosophy in Africa" OR "African tradition" \\
\hline & OR "Humanistic Ethic" OR "African Morality")) \\
\hline & Hits: 63 \\
\hline Google Scholar & Search date: 24 July 2017 \\
\hline \multirow[t]{6}{*}{ Choose search number: additional search } & Selected restrictions: no restriction \\
\hline & Selected search mode: default mode: sort by relevance \\
\hline & $\begin{array}{l}\text { Search string: "African Moral Theory" OR "African Ethics" OR "African Ethic" OR "African ethical } \\
\text { theory" OR "African Moral Framework" OR "African philosophy" OR "Philosophy in Africa" OR }\end{array}$ \\
\hline & "African tradition" OR "Humanistic Ethic" OR "African Morality" ubuntu OR "Ubuntu-oriented" OR \\
\hline & "Ethics of Ubuntu" OR "African ethic of Ubuntu" \\
\hline & Hits: 343 \\
\hline African Journals Online & Search date: 28 January 2019 \\
\hline \multirow[t]{5}{*}{ Choose search number: additional search } & Search string: ((ubuntu OR "Ubuntu-oriented" OR "Ethics of Ubuntu" OR "African ethic of Ubuntu") \\
\hline & AND ("African Moral Theory" OR "African Ethics" OR "African Ethic" OR "African ethical theory" OR \\
\hline & "African Moral Framework" OR "African philosophy" OR "Philosophy in Africa" OR "African tradition" \\
\hline & OR "Humanistic Ethic" OR "African Morality")) \\
\hline & Hits: 11 \\
\hline
\end{tabular}

The focus of this exercise is not to review how individual theoretical formulations of ubuntu may be used to address ethical issues. Rather, the goal here is descriptive. Therefore, studies that highlight how this ethical theory may be used to address a variety of moral issues, as well as studies that integrate aspects of ubuntu ethics to ground or explain concepts such as justice, rights and capabilities, were included only insofar as they provided a substantial description of the nature and core aspects of ubuntu.

In addition, studies that deny the existence of ubuntu - unless in some substantial way they describe its nature - are excluded from this review. As stated previously, it is not within the scope of this study to rescue ubuntu from its critics, or to enter the debate as to the existence of an African moral philosophy. Also excluded from this review are books, book summaries, book reviews and unpublished materials. However, book chapters, encyclopaedia entries, journal publications, inaugural addresses and conference papers that offer substantial and original descriptions of ubuntu are included for the review. Articles which met these selection criteria were pooled together in EndNote database version X6 (Thomson Reuters, Canada).

\section{Data extraction process}

For the data extraction, this study used conventional analysis. Specifically, the study adopted the $\mathrm{Q}$ methodological approach to conduct this review. Q-sort technique is designed for qualitatively sorting a number of individual viewpoints into broader categories by identifying similarities. This approach can show us how viewpoints or expressed opinions are interconnected or related. As Watts and Stenner ${ }^{[40]}$ observe, $\mathrm{Q}$ methodology is primarily an exploratory technique. Its aim is not to prove hypotheses. It can, however, bring a sense of coherence to individual research questions that have many potentially complex and socially contested answers. In summary, Q-sort technique is a useful technique for identifying common themes and sorting them into broad categories. Individual narratives may be used to supplement interpretation or understand the reasoning behind the sorted categories or themes. ${ }^{[40,41]}$ We have adopted this methodological approach because of its vertical and horizontal usefulness.

On the vertical line, it is a useful way of proceeding from a clearly defined research question to method, result and discussion. The research question plays a very important part in any $\mathrm{Q}$ methodological study, since it dictates the nature and structure of the themes or categories to be generated. On the horizontal line, it is a good approach for generating broadly representative opinions or viewpoints expressed by the authors of the reviewed studies as constituting the core aspects of ubuntu, as well as for highlighting differing views. We are not aware of any published study that has previously used Q-sort technique for this purpose, and therefore we can fairly claim that this is the first attempt. 
The conventional analysis was carried out in ATLAS.ti (ATLAS.ti Scientific Software Development $\mathrm{GmbH}$, Germany) to answer the primary research question. The eligibility criteria pooled 4 book chapters, 2 encyclopaedia entries, 1 conference paper and 106 articles published in international peer-reviewed journals for review.

\section{Results}

In this section, we report only our findings regarding the core aspects of ubuntu identified through the review of written and published discourses on ubuntu.

\section{Genre of (moral) philosophy}

A significant number of studies ${ }^{[5,11,17-19,26,42-58]}$ express the idea that ubuntu is a genre of philosophy that one may rightly refer to as African ethics. African ethics is described as a set of values distinctively associated with largely black African people residing in sub-Saharan Africa. These values are based on ethical beliefs, moral judgements or ideas such as prizing communal relationships prevalent among this population, rather than themes such as respect for autonomy or impartial cost-benefit analysis that are prevalent in the West. ${ }^{[4,14]}$ In other words, while notions such as a sense of community may also be found in Western societies, the salient philosophies in the West do not conceive of such ideas as core in prescribing duties in the way societies south of the Sahara do.

There are other ways in which these studies distinguish ubuntu as an African ethics. To call the theory of ubuntu 'African', Metz, for example, explains, does not imply that all sub-Saharan societies have believed it or have been aware of it. ${ }^{[59]}$ It is a philosophical construction by moral theorists, ${ }^{[23]}$ which unifies a wide array of the moral judgements and practices found among many black Africans spanning a large geographical area in sub-Saharan Africa, and over a broad time period, from pre-colonial peoples to contemporary literati.

Consistent with its description as an African ethics, there are a variety of ways in which ubuntu has been described by reviewed studies. They include: African humanism; $;^{[9,46]}$ Afro-communitarian moral perspective or ethic $i_{i, 60,66]}$ humanist or communalistic ethic; $;^{[57]}$ Afro-communalism; ${ }^{[62]}$ African eco-bio-communitarian outlook; ${ }_{i}^{[2]}$ and harmonious monism. ${ }^{[2]}$

\section{Semantic analysis and definition of ubuntu}

Reviewed studies generally agree that the term ubuntu has its roots in the SA Nguni-Bantu oral traditions, and is made up of the prefix ' 'ubu-' meaning being in potency, or an enfolded being, and stem 'ntu' - meaning being in actuality or unfolded being. Although the specific term 'ubuntu' has its roots in the oral traditions of SA, scholars such as West ${ }^{[27]}$ and others ${ }^{[5,63,64]}$ confirm that what is implied by the term extends to other cultures south of the Sahara.

There is also a general impression from reviewed studies that the term ubuntu cannot be adequately conveyed in English. Nonetheless, two common translations of this term are given in these studies. These are 'personhood' and 'humanness'. $9,26,27,55,65]$ For this reason, it can be concluded that ubuntu has something to do with what it means to be truly human - what it means to be a person. Ubuntu, some studies ${ }^{[2,28,66]}$ maintain, refers to the very essence of being human. The antithesis of ubuntu is 'into', meaning a thing. Into results when an individual distances himself/herself from, or engages in acts that compromise the unity of, the community. ${ }^{[9]}$
Dreyer ${ }^{[65]}$ quotes Desmond Tutu as defining ubuntu in the following way:

'When we want to give high praise to someone we say, ' $Y u, u$ nobuntu'; he or she has ubuntu. This means that they are generous, hospitable, friendly, caring and compassionate. They share what they have. It also means that my humanity is caught up, is inextricably bound up, in theirs. We belong in a bundle of life ... I am human because I belong, I participate, I share. A person with ubuntu is open and available to others, affirming of others, does not feel threatened that others are able and good, for he or she has a proper self-assurance that comes with knowing that he or she belongs in a greater whole and is diminished when others are humiliated or diminished, when others are tortured or oppressed, or treated as if they were less than who they are.'

In this way, one's humanity is expressed through one's relationship with others, and the humanity of others is in turn expressed through recognition of the individual's humanity. ${ }^{[2,67]}$ Hence the Zulu aphorism 'umuntu ngumuntu ngabantu' (in Xhosa, 'ubuntu ungamntu ngabanye abantu'). This aphorism has been translated in a variety of ways: 'I am because we are'; 'a person is a person through other persons'; 'a human being is a human being only through its relationships to other human beings'; 'we are, therefore I am, and since I am, therefore we

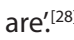

\section{Umuntu ngumuntu ngabantu: Meaning and range of implications}

The broad meanings implied by the maxim umuntu ngumuntu ngabantu identified in reviewed studies range from metaphysical to prescriptive claims.

First, some reviewed studies argue that the maxim expresses a descriptive claim (in part), which is the view that one's identity as a human being causally and even metaphysically depends on a community. Cilliers ${ }^{[9]}$ and Forster, ${ }^{[68]}$ for example, express the view that the aphorism articulates a factual description of humanity as a being-with-others. An individual cannot survive on his or her own, ${ }^{[25]}$ but needs others. Hence to be a human being is to be a being-withothers.

The above descriptive claim is not common to all reviewed studies. What is commonly accepted is the view that the maxim umuntu ngumuntu ngabantu expresses a moral principle that prescribes that one ought to exhibit certain characteristics: ${ }^{[21,25,42,68-71]}$ to prize harmonious/communal or interdependent relationships $i_{i}^{[10,57,72]}$ to develop one's personhood through our availability to or affirmation of others; ${ }^{[1]}$ to develop one's humanness through communion with others (or by being a being-with-others); and to live for others or seek goals which do not put others and the community in jeopardy. ${ }^{[73-75]}$

In addition, this review also shows that in ubuntu, the expression 'communing with others' is not limited to actual living human beings, but also involves a fundamental connectedness of all lives in the natural and spiritual environments. Hence, ubuntu is an ethical theory in which the natural and spiritual worlds are united. This ethical theory is based on a (totemic) system whereby an individual ought to see him-/herself as related and interrelated with the spiritual world on the vertical line, as well as other non-human species and the wider environment on the horizontal line. ${ }^{[28,56,68,76-82]}$ Breems $^{[1]]}$ and Dolamo ${ }^{[80]}$ imply that $n t u$ has continuities with other categories - the 
unborn, plants, animals, spirits, transcendent or supernatural forces, and so on. Forster ${ }^{[68]}$ expresses this differently: 'the unity and harmony of personhood expressed in ubuntu stretches from the world seen through the naked eye to the world of ancestors, the spirit world.'

Consequently, in ubuntu, personhood/humanness is in a symbiotic relationship, or is inextricably bound up, with the dynamic (bio) physical and spiritual worlds. However, although an individual is involved in a web of interconnectedness and relatedness with the extended (bio)physical and spiritual worlds, one's present and actual web of communion such as present family ties, some scholars ${ }^{[83]}$ add, takes priority over future or possible relationships.

In light of this generally accepted prescription to exhibit certain characteristics, the theorisation around ubuntu, Koenane and Olatunji ${ }^{[84]}$ observe, is best classified as a narrative of becoming, as opposed to its competing classification as a narrative of return. Debate around this classification has caused significant controversies among certain scholars. ${ }^{[1,22,60,85-87]}$ In other words, disagreement exists among scholars regarding the classification of ubuntu as a narrative of return. What 'return' means here is also a source of controversy: while some scholars believe the phrase implies a return to some glorious past (the era of destination being the precolonial period), others argue that the phrase implies retrieving values from the past and adapting them to address contemporary issues. Kubow and Min, ${ }^{[85]}$ quoting Gade, specifically assert that ubuntu 'functions as a call to Africanisation, embodied in an effort to "formulate a foundation of politics that consists of traditional African humanist or socialist [communal] values"'. Others, such as Matolino and Kwindingwi, ${ }^{[86]}$ criticise this call to Africanisation. According to Matolino and Kwindingwi, ${ }^{[86]}$ this appeal to return to some glorious past is neither new, nor has it been successful. Rather it has only led to many individuals living undignified lives: to the suppression of political space, and to tyrannical dictatorships that are developed in pursuit of the oneparty state, in which citizens are denied the opportunity to form political aspirations other than those the leadership has prescribed as the politically correct way of being. Finally, in their view, advocates of ubuntu as a narrative of return view African life as monolithic, both in its interpretation, and how it is lived.

Koenane and Olatunji ${ }^{[8]]}$ prefer to classify ubuntu differently. In their words:

ubuntu is not about the 'narrative of return', but constitutes a stillviable way of life in which an individual learns to be human and to live responsibly and harmoniously with others. A more plausible, satisfactory description of ubuntu is a 'narrative of becoming human', a narrative of seeking the truth, as seen in the SA Truth and Reconciliation Commission, which was underpinned by ubuntu epistemology.

Koenane and Olatunji's ${ }^{[84]}$ view appears to be the commonly accepted one (and a uniting principle) in the reviewed literature. Ubuntu is an ethical theory that asks individuals to become a certain sort of person/human being: to exhibit certain virtues, or relate communally/harmoniously by sharing a way of life with others (along the vertical and horizontal lines), and by caring for their quality of life; to enhance the relational capacity of others; to live a genuinely human life; and to value relationships of interdependence. Relationality, interdependence, friendliness, communalism and personhood/humanness are all value-laden key concepts in this philosophy.

\section{Communal character of ubuntu}

There are two dominant views regarding the nature of community in the ethical literature on ubuntu. These concern whether community is ontologically prior to the individual or coterminous with the individual. $A$ is ontologically prior to $B$, if it precedes $B$ in being or if $B$ depends on $A$ for its existence.

There are two dominant views with regard to ontological priority. The first regards the community as a basic value (good for its own sake), and necessary for one's development of personhood/ humanness. The second opinion regards the community as an instrumental value (merely as a means to an end, such as personhood or humanness). ${ }^{[28,88,89]}$ In this regard, the community has no intrinsic value, but is valuable for achieving humanness or personhood.

The view of the individual and the community as coterminous is a mutually constitutive one, in which the good of the individual and that of the community are interwoven such that the individual's subjectivity is not solely determined by the community but co-substantively constituted with that of the community. ${ }^{\left[{ }^{[1]}\right]}$ According to this view, by advancing the good of the community, an individual concomitantly advances his own good.

Regardless of the differing opinions regarding the nature of community, the general opinion in the reviewed literature is that communal relationships take priority and are of overriding importance in this philosophy. Note, however, that the term community, as used by the reviewed studies, does not refer to an existing society 'out there' in the world. Rather, the commonly expressed view is that community refers to an ideal way of relating to others in a society. ${ }^{[0]}$ Similarly, the term community does not imply that moral norms are determined by a group's culture, that is, that what is right is what the majority of people in the society want. According to one study, ${ }^{[0]}$ these are Western forms of relativism and communitarianism. Rather, community is an (objective) standard that should guide what the majority wants, or what moral norms become central. ${ }^{[21,23,62,74,90]}$

In light of the above, the communal character of ubuntu, the studies point out, does not imply that individual rights are subordinated. Rather it implies that in communal relationships, the individual, as Lutz ${ }^{[55]}$ and others ${ }^{[49,69]}$ observe, does not pursue the common good over his own good, but pursues his own good through pursuing the common good. In the literature, ${ }^{[16,49,56,63,72,91,92]}$ the communal character of ubuntu does not wipe away individuality (in the sense of everyone having the same frame of mind); rather, one's individuality persists. In this African ethics, each individual contributes his experience, abilities, knowledge and strategies to the final social goal, and where there are disagreements, such disagreements are negotiated through indaba(s) - or discussions among all members of the community - in order to arrive at a consensus. ${ }^{[93]}$ It is in respect of this feature that some studies distinguish ubuntu as being less individualistic and anti-egoistic, as forbidding the seeking of personal goods without regard for others, and as more communal than Western ethics. ${ }^{[11,64,78]}$ Lutz, ${ }^{[55]}$ quoting Turaki, expresses this point well when he remarks: '[In African ethics], people are not individuals, living in a state of independence, but part of a community, living in relationships and interdependence.'

In addition, it is also in this regard that ubuntu is said to be essentially relational. In other words, relationships have special moral importance, in contrast to Western ethical frameworks such as principlism, which makes no essential reference to others, but only 
the given individual, this African ethics requires individuals to interact harmoniously with others.

There are other ways in which African scholars distinguish ubuntu from Western ethics. Behrens, ${ }_{1}^{[7]}$ for example, argues that the principle of respect for autonomy in principlism 'is grounded in an excessively individualistic worldview ... it is concerned only with individual decision-making ... [whereas] it is central to the worldview of most Africans that community is prized and that individuals are bound up with their communities.'

Hence the maxim umuntu ngumuntu ngabantu, Metz ${ }^{[8,94]}$ notes, is to be understood as a claim to live in harmonious or communal relationships 'in which people identify with each other and exhibit solidarity with one another'. Typical discussions around the nature of community, a reviewed study ${ }^{[75]}$ claims, coalesce around these two themes: identifying with others, and exhibiting solidarity with others.

Identifying with others implies thinking of oneself as a we (cognition), developing a sense of togetherness or expressing shame/pride in what the group does (emotions), engaging in joint projects (conation), adopting goals consistent with those of others (volition) and finally, co-ordinating behaviour to realise shared ends (motivation). ${ }^{[4,11,16,17,27,42,43,57,62,63,67,69,80,83,90,95-101]}$ Migheli[16] $^{[16]}$ classifies this 'we' thinking into 'we' mode and the 'pro-group I' mode. The former is team thinking: here one reasons within and for the group. The latter occurs when one keeps one's individuality and reasoning, but adopts the preferences of the group. Exhibiting solidarity involves providing mutual aid, empathic awareness of others' conditions, exhibiting positive emotions/motives toward others, helping others for altruistic reasons and acting for the sake of others (which involves acting in ways that are likely to be for the good of others).

Though identity and solidarity are conceptually distinct, the communal character of ubuntu requires a blend of these two things, and this blend is what one study ${ }^{[94]}$ refers to as friendship or love. In Metz's ${ }^{[100]}$ ethics of friendship, however, ending unfriendliness takes precedence over promoting friendliness, if one must choose between these two. In order to act in accordance with ubuntu, there is a primary obligation to be friendly oneself or to end unfriendliness, and a secondary obligation to promote new friendships. ${ }^{[19]}$ Since 'relationality requires that relationships or properties of relationships have moral primacy, ${ }^{\prime[89]}$ the basic reasoning that one ought not to engage in unfriendly acts appeals not to facts internal to an individual or the victim, but to facts about the way individuals interact. ${ }^{[19]}$ Unfriendly interactions are inappropriate ways of relating, since they are not other-regarding.

A failure to be friendly with others - along the vertical and horizontal lines - results in alienation, ill-will and/or the devaluation of oneself to the level of an animal. ${ }^{100]}$ 'A loner', Mnyaka and Mothlhabi ${ }^{[56]}$ write, 'is always viewed with suspicion. He is inkomo edla yodwa (a cow that grazes on its own).'

\section{Ubuntu's sense of humanness/personhood}

In many of the reflections on ubuntu, personhood and humanness are essentially moralised, so that one becomes more or less of a person or human, firstly, by exhibiting moral traits that humans are in a position to exhibit in a way no other beings can, and secondly, through interdependent relationships. The former describes what a $\mathrm{real} /$ complete person in the philosophy of ubuntu looks like, while the latter describes how one develops ${ }^{[97]}$ this personhood/humanness.
In the ethical literature on ubuntu, firstly, the expression 'a person is a person' in the maxim umuntu ngumuntu ngabantu implies that one becomes a person when one displays certain values. Haegert ${ }^{[17]}$ describes these values in the following way: 'a person becomes more of a person through a certain kind of person, one who is himself or herself integrated and self-donating, aware, determining, free and spiritual.'

The essential relational character of ubuntu has great significance for this theory's view of how one develops one's humanness and personhood. Mboti ${ }^{[101]}$ and others ${ }^{[102]}$ express this point by emphasising that the idea of community or relationality is the heart of traditional African thinking regarding humanity and personhood. Humanness and personhood are developed through others, such that one becomes more or less of a human being (person) according to how one values friendship or harmony with others, that is, according to how one values other-regarding behaviours, exhibits solidarity and thinks of oneself as a'we' as opposed to an 'I!' $2,4,14,43,47,5,5,57,63,66,68,75,103]$

In light of the above, the maxim umuntu ngumuntu ngabantu implies that the pathway to authentic development of one's personhood/humanness is never something that can be achieved in opposition to others. Rather, authentic personhood/humanness is essentially achieved through others, by relating communally with others, comprising both the world seen by the physical eyes and the spiritual world. ${ }^{[46]}$ One who fails to exhibit humanness/personhood is considered a non-person or an animal. However, one study ${ }^{[83]}$ remarks that '[t]his way of speaking does not mean that wicked or unjust individuals are literally no longer human, namely, no longer the subject of human rights; it means rather that they have failed to exhibit what is valuable about human nature to any significant degree.'

Humanness/personhood is essentially developed through communal relationships: one does not accomplish personhood or humanness by oneself. The community - in which the physical and spiritual worlds are fundamentally united - must also be involved, requiring individuals to embrace a socially generated body of norms. ${ }^{[23,56,95]}$ For this reason, one is not only a subject of relationship, but an object of relationship as well: 'we are, therefore I am, and since I am, therefore we are. ${ }^{[28]}$ Thus participation in the life of the community and reciprocal compassion on the part of the community are two key features of relationship in ubuntu philosophy. Dolamo ${ }^{[80]}$ argues this point when he says: '[i]t must be recalled that African ethics ... describes a person as a process of coming into existence in the reciprocal relatedness of individual and community, where the latter includes not only the deceased but also God.' 'Harmony', Tschaepe ${ }^{[57]}$ adds - in addition to developing the individual 'provides the community with stability from which persons develop. Solidarity provides the community with identity that contributes to the identification of the person as a person.'

The studies, however, express varying opinions regarding the manner in which this development of personhood takes place. Some ${ }^{[47,68,80,83,95]}$ express the view that the development of personhood follows a certain process. In Ramose's opinion, for example, 'personhood is something that has to be achieved, and is not given simply because one is born of human seed ... thus it is not enough to have before us the biological organism ... we must also conceive of this organism as going through a long process of social and ritual transformation until it attains the full complement of excellences 
seen as truly definitive of man.' ${ }^{22,52]}$ This view has been criticised by Eze, ${ }^{[51]}$ who argues that personhood/humanness is not achieved via a process but, as stated in the previous section, is co-substantively constituted with the community. This way, the community guarantees the individual's subjectivity, and the individual guarantees the community's survival by promoting her common good.

Finally, the capacity to be both the subject and object of friendship, some studies ${ }^{[4,94]}$ point out, is essential for acquiring a higher (full) moral status, which cannot be achieved by being merely the object of friendship. One is the subject if one can think of oneself as 'we', and the object if other humans can think of one as a part of a 'we'.

We note here that the studies do not seem to share the same view on how one gains (full) moral status: while scholars such as Mnyaka and Mothlhabi ${ }^{[56]}$ see actual participation in communal relationship as essential for developing one's status or personhood/humanness, and other scholars such as Dolamo ${ }^{[80]}$ and Forster ${ }^{[68]}$ see a continuity in the unity and harmony of personhood that is expressed by ubuntu from the fetus in the womb to the elderly dementia sufferer and even the world unseen, Metz prefers to limit his view of individuals who have full moral status only to those who are capable of being the subject and object of relationship. On Metz's ${ }^{[94]}$ account, beings in the womb during the first 2 months of pregnancy, who merely have the potential for communal relationships and not a capacity for such, lack moral status. To this list, one could also add others who, owing to illness or disease, have lost the capacity to be the subject and/or object of communal relationships (this does not include those who do not in fact live in a community, such as hermits, who retain this capacity despite their circumstances). Some examples include advanced dementia patients. One has moral status to the extent that one is capable of being part of a communal relationship of a certain kind - what Metz calls modal relationality (that is, what is required is for one to be capable of being in communal relationship and not that one is necessarily in an actual communal relationship). ${ }^{[94]}$ As Metz ${ }^{[104]}$ puts it, "[t]o be "capable" of being part of a communal relationship means being able in principle, i.e, without changes to a thing's nature'. To this end, one has (human) rights to the extent that one has full moral status, that is, the extent to which one can be both a subject and an object of a communal relationship. .

In light of the above, abortion within 2 months of conception is justified. Metz ${ }^{[94]}$ acknowledges that his view on abortion is one that may be inconsistent with the moral intuition that pro-life activists espouse. There may be other implications of Metz's account of moral status. For example, killing an advanced dementia patient who has lost the capacity for communal relationships, may, in itself, not necessarily be morally wrong based on this view, since such beings are no longer capable of thinking of themselves as a 'we'. In addition, given Metz's ${ }^{[104]}$ view of those who have human rights, advanced dementia patients do not have rights. It may, however, be wrong to kill advanced dementia patients if this will negatively affect others who still think of the patient as a part of a 'we'. In other words, it is wrong because of the way others are likely to feel about the death of the objects of their communal relationships.

Metz ${ }^{[94]}$ seems to acknowledge this implication by observing that 'the African theory does appear to entail that severely mentally incapacitated human beings and extreme psychopaths lack a dignity comparable to ours, for they are incapable of being subjects of a communal relationship.'This implication is inconsistent with the basic intuition many have about dementia patients, who most people still think of as persons and to whom they accord a certain moral status in response to this recognition. Perhaps Behrens ${ }^{\prime[7]}$ differentiation between 'persons with moral agency' and 'persons without moral agency' can better account for this intuition in a way that avoids distasteful implications. Persons with moral agency are those who can be self-determining, as well as capable of relating in appropriate ways with others. Persons without moral agency are those who may or may not be self-determining - who lack the capacity for reasoning or whose capacity for reasoning is severely impaired. In Behrens' ${ }^{[7]}$ account, both groups of persons have moral status, and we have an obligation - similar to those specified in the Belmont Report's principle of respect for persons - to respect the self-determination of persons with agency, and to protect those without agency from exploitation and harm.

\section{Interconnectedness/interdependence in ubuntu}

In the discussions around interconnectedness and interdependence in ubuntu, there is a consensus that every person forms a link in a chain. Venter ${ }^{[78]}$ quotes Teffo as arguing this point in the following words: in ubuntu, 'every individual forms a link in a chain of vital forces, a living link, active and passive, joined from above to the ascending line of his ancestry and sustaining below him the line of his descendants.' An interdependent community is one in which individuals can only discover who they are through others, while recognising the distinctive identity of individuals. ${ }^{[79]}$ Finally, interdependence/interconnection also means that one's humanity is caught up or inextricably bound up with and intertwined in, that of others. ${ }^{[2,54,92,105]}$ For this reason, when a community is broken, the individual is also broken. Restoration of the community also cannot occur without the healing of the individual.

In summary, this review of existing ethical literature on ubuntu philosophy shows that each person is never alone, but is constituted by webs of interconnection (through shared identity), interrelatedness, intersubjectivity (mainly by cognition, that is, thinking of oneself as 'we') and interdependence (whereby one develops personhood/ humanness through others). ${ }^{[68]}$

\section{Source of moral motivation}

The consensus of the theoretical descriptions of published discourses on ubuntu, as evident above, is that this ethical theory is essentially relational. Thus the maxim umuntu ngumuntu ngabantu in the reviewed ethical literature implies that the morally right action is one that honours communal relationships, reduces discord or promotes friendly relationships with others, and in which the physical world (horizontal line) and the spiritual world (the vertical line) are fundamentally united. In other words, the morally right action is one that connects, rather than separates.

This captures the core aspects of what most scholars agree would constitute the definition of a morally right action in this ethic. Some studies ${ }^{[75,97]}$ distinguish this norm from Western norms such as Kantianism, which defines a morally right action as that which enhances others' capacity for autonomy, or utilitarianism, which defines wrong actions as wrong insofar as they fail to promote the general welfare. Ubuntu, on the other hand, defines right actions as right insofar as they promote friendly relations among individuals, enhance friendliness or the capacity for the same, and 
connect individuals. In this regard, it would be wrong to be hostile towards others, unless such unfriendly action is necessary to counter comparable misconduct on their part, or to protect those threatened by their hostility.

In light of the preceding paragraphs, the common view in the literature is that fellowship, interconnectedness, interdependence, reconciliation, relationality, community, friendliness, harmonious relationships and other-regarding actions have special significance in evaluating the morality of an action. $[2,4,13,14,19,21,23,25,43,56,57,67,71,78,84,90,94,104,106-112]$ If the self were to be the basis for right action, then the self could justify any action as long as it benefits the self. On this relational account of morality, an other-regarding view fundamentally determines the way the self should behave. ${ }^{[19]}$ Ubuntu invites one to develop the self by prizing other-regarding actions. Actions are wrong when they constitute a failure to regard others, or they jeopardise friendship with others. In Wiredu's ${ }^{[113]}$ view, for example, one is obliged to tell the truth because not to do so would threaten one's very status as person, as well as the very status of the community. ${ }^{[57]}$ On the other hand, the obligation to tell the truth disappears in cases where the disharmony of the community would result from truth-telling. In other words, the obligation to tell the truth exists when communal harmony and/or the individual's personhood/humanness is not threatened by doing so. The immediately preceding point is the humanistic foundation added by Wiredu to this African ethics. Unlike Kant, who grounds the obligation to tell the truth in his categorical imperative, Wiredu grounds this obligation to tell the truth, as well as other moral actions, in the survival or harmony of the human community. In Wiredu's ${ }^{[113]}$ view, the survival and harmony of the human community is the ground for morally right action. It is in promoting the harmony of the community that individuals develop their personhood and humanness.

Finally, in this essentially relational ethics, emotions are also involved in deciding which actions are appropriate. This review shows that acting rightly and being the best sort of person necessarily involve exhibiting certain emotions, such as empathising with others and showing concerns for others' wellbeing. ${ }^{[8]} \mathrm{A}$ person who fails to exhibit empathy at the misfortune of others is said to have no heart (nta mutima agira). ${ }^{[114]}$

\section{Discussion}

The presentation of the results above (and the discussion that follows here) was guided by the study's descriptive objective, which is to contribute towards a definition of ubuntu that encompasses the common themes that run across existing, and sometimes competing, interpretations of ubuntu.

The core aspects of ubuntu, as described in the reviewed ethical literature, include the essentially relational nature of this ethical theory, which prizes relationship[s] of interdependence, fellowship, reconciliation, relationality, community friendliness, harmonious relationships and other-regarding actions, and in which actions are morally right to the extent that they promote social integration and interconnectedness, honour communal relationships or the capacity for the same and reduce discord or promote friendly relationships with others, and in which the physical world (horizontal line) and the spiritual world (vertical line) are fundamentally united. This formulation has great potential for contributing towards an ethical framework developed around this African moral theory, for considering (bio)ethical issues more globally and ethical dilemmas in the clinical context in particular. In addition, this formulation supplements previous attempts at a literature review of the scope of ubuntu by correcting for the methodological shortcomings inherent in these studies. The methodological approach of this study is more likely to ensure internal validity (reproducibility) and external validity (rendering this formulation more conducive for external use).

Specifically, the formulation of ubuntu described above may be used to justify a breach of ethical principle(s) - for example, where autonomy conflicts with beneficence or any of the other principles where such a breach favours the action that enhances communal relationships, or the capacity for the same. As such, this framework could usefully supplement principlism as the dominant approach to ethical decision-making in clinical contexts. On the basis of this theoretical formulation, one could derive a rule that states: 'A breach of an ethical principle is justifiable if, on the balance of probabilities, such a breach is more likely to enhance communal relationships, or the capacity for the same, and end ill-will'. For example, dentists, mental healthcare professionals and paediatricians who report experiencing conflict between their professional duty to report abuse and the patient's request not to do the same, as reported in some studies ${ }^{[115-117]}$ can appeal to this formulation for guidance. These professionals can resolve this conflict by appealing to this formulation, which prizes ending unfriendliness (such as the abuse of a minor), since this is an inappropriate way of relating.

This formulation may also be used to ground the global United Nations sustainable development goals ${ }^{[118]}$ to end poverty, care for the planet and ensure prosperity for all. According to this study's construction of the theoretical formulation of ubuntu, human beings are in a web of relationships and interconnectedness in which we are to care for others' well-being. The other comprises all beings and things on the vertical and horizontal lines. This framework, it may be argued, is suitable for grounding ethical duties to protect the environment by collectively working towards ending global climate change. ${ }^{[7]}$ This construction of ubuntu could be used to support a moral rule that claims that a failure to exhibit caring concern for the physical environment (with whom the human person is in a relationship on the horizontal line) is itself a devaluation of oneself, since through such an act one fails to end unfriendliness (towards the environment).

Furthermore, this theoretical formulation has great potential for addressing ethical challenges around truth-telling within the clinical context. Clinicians who face ethical challenges around truth-telling within the clinical context, as reported by some studies, ${ }^{[119,120]}$ may appeal to this theoretical formulation to address those ethical challenges. For example, one could develop a guideline, based on this formulation, which supports truth-telling when, on the balance of probabilities, this is likely to enhance human relationships and interconnectedness, or honour the patient's existing relationships and capacity to relate. In making decisions about truth-telling, existing relationships, or relationships of long standing, should take priority. Finally, this theoretical formulation also provides justification for actions such as rebellion, when it is necessary to end unfriendliness, and it grounds concepts such as (restorative) justice. In this regard, justice may be conceived as a process of healing and making right (as far as possible), where all those affected - perpetrators and victims are given the opportunity to come together to seek reconciliation and discuss ways of rectifying the wrong. 
Notwithstanding the potential advantages and uses of this formulation, as discussed above, the present study has other limitations in addition to those previously stated. The search for relevant materials was performed in PubMed, PhilPapers and Google scholar, with additional screenings in Philosopher's Index and Stellenbosch University's online library database. This may have resulted in the unintended exclusion of potentially relevant studies indexed by other databases and search engines. The justification for searching these databases is that a significant quantity of the ethical literature on ubuntu has been published by the South African Journal of Philosophy and other journals that are indexed by these databases and search engines - particularly PhilPapers and Google Scholar thus leaving very little outside of these databases and search engines. In addition to this, we are also aware that the strict screening process, as well as the eligibility conditions, may have also resulted in the exclusion of other potentially relevant materials. For example, the decision to pool only studies published in English may have resulted in the exclusion of potentially relevant studies published in other languages.

Additionally, we acknowledge that excluding books from this systematic review is another limitation. However, the exclusion of books does not significantly affect the quality of the study, as many of the books on this topic have been published by authors who have themselves explained their ideas in articles published in international peer-reviewed journals, which have been included in this study. Other authors whose works appeared in this review have made significant references to books in their works, and some of these references and quotes appear in this review. Furthermore, recent engagements with ubuntu have largely appeared in published journal articles, and many of these have been indexed by the databases in which we conducted searches. This systematic review is a contribution towards providing a definition of ubuntu that encompasses the common themes which runs across existing, and sometimes competing, interpretation of the same. No one single systematic review can complete this enormous objective, but this review seeks to take a first step in this regard. We recommend future studies to further strengthen the outcome of this review. Notwithstanding these limitations, we are optimistic that this formulation captures what most ubuntu scholars would accept as constituting the core aspects of this ethical theory.

Finally, this study notes that merely providing (by way of a systematic review) a theoretical formulation of ubuntu that encompasses the common themes that run across existing, and sometimes competing, interpretations of this theory, does not in itself imply that it is valuable, and particularly that it will be useful in practice. The latter requires evaluative argument. Future studies can build on the outcome of this review by providing such arguments, and by applying this theoretical formulation to address various pressing global (bio)ethical issues.

\section{Concluding}

The review of existing studies on ubuntu has identified this ethical theory as an essentially relational ethics that prizes relationships of interdependence, fellowship, reconciliation, relationality, community friendliness, harmonious relationships and other-regarding actions, in which actions are morally right to the extent that they honour the capacity to relate communally, reduce discord or promote friendly relationships with others and in which the material world (horizontal line) and the spiritual world (the vertical line) are fundamentally united.

The above theoretical formulation best captures the core aspects of this theory, and it is an important methodological contribution to the written discourse on ubuntu. Further research, however, is needed to properly highlight the contrasting views among ubuntu scholars. Research is also needed to test how properly action-guiding this formulation is in particular contexts. Nonetheless, scholars, health professionals, policy makers and others should be aware that a useful alternative to Western theories of right action(s) exists in the global South that may be embraced to enhance ethical decision-making in the clinical context, as well as to address a variety of (bio)ethical issues more globally.

Acknowledgements. The authors are grateful to the reviewers for their critical feedback and comments, which have led to the improvement of this study. The authors are equally grateful to Prof. Kris Dierickx for reviewing a previous draft of the study.

Author contributions. $\mathrm{CE}$ and $\mathrm{SH}$ developed the project proposal upon which this study is based. CE and SH adapted a proposal for this particular study, as well as developed the method section of this work. CE was responsible for selecting articles for review, but discussed the process extensively with $\mathrm{SH}$ to ensure consistency in the inclusion and exclusion criteria. Two revisions of the process were done by $\mathrm{SH}$ to ensure consistency with selection criteria, as well as with the larger project aims and objectives. Both authors critically revised the manuscript, raised no objections for its submission for publication, and are responsible for its intellectual content.

Funding. None.

Conflicts of interest. None.

1. Boissevain J, Richardson JW, Netshandama V, et al. The quest for ubuntu: Water and Health in Limpopo (WHIL) Partnership. Widening Participation Lifelong Learning 2013;15(4):26-45. https://doi.org/10.5456\%2FWPLL.15.4.26

2. Etieyibo E. Ubuntu, cosmopolitanism, and distribution of natural resources. Philos Papers 2017;46(1):139-162. http://doi.org/10.1080/05568641.2017.1295616

3. Komparic A. The ethics of introducing GMOs into sub-Saharan Africa: Considerations from the sub-Saharan African theory of ubuntu. Bioethics 2015;29(9):604-612 https://doi.org/10.1111/bioe.12191

4. Metz T. African and Western moral theories in a bioethical context. Dev World Bioeth 2010;10(1):49-58. https://doi.org/10.1111/j.1471-8847.2009.00273.x

5. MetzT. An African theory of bioethics: Reply to MacPherson and Macklin. Dev World Bioeth 2010;10(3):158-163. https://doi.org/10.1111/j.1471-8847.2010.00289.x

6. Ewuoso C. Managing ethical challenges around misattributed parentage within the clinical context: Insights from an African moral theory. Dev World Bioeth 2018;19(1):36-44. https://doi.org/10.1111/dewb.12196

7. Behrens KG. A critique of the principle of 'respect for autonomy', grounded in African thought. Dev World Bioeth 2017;17(2):126-134. https://doi.org/10.1016/j. jpainsymman.2015.05.011

8. Marston JM. The spirit of ubuntu in children's palliative care.J Pain Symptom Manage 2015; 2015;50(3):424-7. https://doi.org/10.1016/j.jpainsymman.2015.05.011

9. Cilliers, J. In search of meaning between ubuntu and into: Perspectives on preaching in post-apartheid South Africa. A paper presented at the Eighth International Conference of Societas (Societas Homiletica), Copenhagen, 2008.

10. Gade C. The historical development of the written discourses on ubuntu 1. S Afr J Philos 2011;30(3), 303-329. https://doi.org/10.4314/sajpem.v30i3.69578

11. Breems, B. Relational being as icon or communal freedom: Southern Africa's ubuntu. J Sociol Christian 2016;6(2):56-79.

12. Hoffmann N, Metz T. What can the capabilities approach learn from an ubuntu ethic? World Dev 2017;97:153-164. https://doi.org/10.1016/j.worlddev.2017.04.010

13. Metz T. The final ends of higher education in light of an African moral theory. Philos Edu 2009:43(2):179-201. https://doi.org/10.1111/j.1467-9752.2009.00689.x

14. Metz T. Higher education, knowledge for its own sake, and an African moral theory. Stud Philos Edu 2009;28(6):517-536. https://doi.org/10.1007/s11217-009-9141-7 
15. Praeg L. An answer to the question: What is [ubuntu]? S Afr J Philos 2008;27(4):367385. http://doi.org/10.4314/sajpem.v27i4.31525

16. Migheli M. Ubuntu and social capital: A strong relationship and a possible instrument of socio-economic development. Cambridge J Econ 2017;41(4):12131235. http://doi.org/10.1093/cje/bew070

17. Haegert S. An African ethic for nursing? Nurs Ethics 2000;7(6):492-502. https://doi. org/10.1177/096973300000700605

18. Metz T. The motivation for 'Toward an African Moral Theory'. S Afr J Philos 2007;26(26):331-335. https://doi.org/10.4314/sajpem.v26i4.31490

19. Metz T. Ubuntu as a moral theory: Reply to four critics. S Afr J Philos 2007;26(4):369387. http://doi.org/10.4314/sajpem.v26i4.31495

20. Eze M. What is African communitarianism? Against consensus as a regulative ideal. A Afr J Philos 2008;27(4):286-299. https://doi.org/10.4314/sajpem.v27i4.31526

21. Nkondo GM. Ubuntu as public policy in South Africa: A conceptual framework. Int J Afr Renaissance Stud - Multi- Inter-Transdisciplinarity 2007;2(1):88-100. http://doi. org/10.1080/18186870701384202

22. Matolino B. A response to Metz's reply on the end of ubuntu. S Afr J Philos 2015;34(2):214-225. https://doi.org/10.1080/02580136.2015.1035857

23. Metz T. African Ethics [encyclopaedia entry]. International Encyclopedia of Ethics. Hoboken, NJ: John Wiley Sons, Ltd., 2013.

24. Gade CBN. The historical development of the written discourses on Ubuntu. S Afr J Philos 2011;30(3):303-329. https://doi.org/10.4314/sajpem.v30i3.69578

25. Hoffmann N, Metz T. What can the capabilities approach learn from an ubuntu ethic? A relational approach to development theory. World Dev 2017;97, 153-164. http://doi.org/10.1016/j.worlddev.2017.04.010

26. Hailey J. Ubuntu: A literature review. London: Tutu Foundation, 2008.

27. West A. Ubuntu and business ethics: Problems, perspectives and prospects. J Bus Ethics 2013;121(1):1-15. https://doi.org/10.1007/s10551-013-1669-3

28. Gade C. What is ubuntu ? Different interpretations among South Africans of African descent. S Afr J Philos 2012;31(3):484-503. https://doi.org/10.1080/02580136.201 2.10751789

29. Rother Terezinha E. [Systematic literature review $X$ narrative review]. Acta Paul Enferm 2007;20(2):vii-viii. http://doi.org/10.1590/S0103-21002007000200001

30. Russell $R$, Chung $M$, Balk EM, et al. Issues and challenges in conducting systematic reviews to support development of nutrient reference values. Workshop Summary: Nutrition Research Series, Vol. 2. Rockville, MD: AHRQ Publicationss; 2009.

31. Cronin $\mathrm{P}$, Ryan $\mathrm{F}$, Coughlan M. Undertaking a literature review: A stepby-step approach. Br J Nurs 2008;17(1):38-43. http://doi.org/10.12968/ bjon.2008.17.1.28059

32. Collins JA, Fauser BC. Balancing the strengths of systematic and narrative reviews. Hum Reprod Update 2005;11(2):103-104. http://doi.org/10.1093/humupd/ dmh058

33. Parris DL, Peachey JW. A systematic literature review of servant leadership theory in organizational contexts. J Bus Ethics 2013;113(3):377-393. http://doi.org/10.1007/ s10551-012-1322-6

34. McDougall R. Systematic reviews in bioethics: Types, challenges, and value. J Med Philos 2014;39(1):89-97. http://doi.org/10.1093/jmp/jht059

35. Mertz $M$, Strech $D$, Kahrass $H$. What methods do reviews of normative ethics literature use for search, selection, analysis, and synthesis? In-depth results from a systematic review of reviews. Syst Review 2017;6(1):261. http://doi.org/10.1186/ s13643-017-0661-x

36. Mertz $M$, Kahrass $H$, Strech D. Current state of ethics literature synthesis: $A$ systematic review of reviews. BMC Med 2016;14(1):152. http://doi.org/10.1186/ s12916-016-0688-1

37. Pae CU. Why systematic review rather than narrative review? Psychiatry Investig 2015;12(3):417-419. http://doi.org/10.4306/pi.2015.12.3.417

38. Liberati A, Altman DG, Tetzlaff J, et al. The PRISMA statement for reporting systematic reviews and meta-analyses of studies that evaluate healthcare interventions: Explanation and elaboration. PLoS Med. 2009;6(7):1-28.doi:10.1371/ journal.pmed.1000100.

39. Pillastrini P, Vanti C, Curti S, et al. Using PubMed search strings for efficient retrieval of manual therapy research literature. J Manipulative Physiol Ther 2015;38(2):159166. https://doi.org/10.1016/j.jmpt.2014.11.005

40. Watts $S$, Stenner P. Doing Q methodology: Theory, method and interpretation. Qual Res Psychol 2005;2(1):67-91. http://doi.org/10.1191/1478088705qp022oa

41. Roberts JK, Hargett CW, Nagler A, et al. Exploring student preferences with a Q-sort: The development of an individualised renal physiology curriculum. Adv Physiol Educ 2015;39(3):149-157. http://doi.org/10.1152/ advan.00028.2015.

42. Metz T. Toward an African moral theory. J Political Philos 2007;15(3):321-341. http:// doi.org/10.1111/j.1467-9760.2007.00280.x

43. Baker D-P. Rebellion and African ethics. J Military Ethics 2016;15(4):288-298. http:// doi.org/10.1080/15027570.2017.1284462

44. Battle M. A theology of community: The ubuntu theology of Desmond Tutu. Interpretation 2000:54(2):173-182 https://doiorg/10.1177\%2F002096430005400206
45. Beer SD. Ubuntu is homeless: An urban theological reflection. Verbum et Ecclesia 2015;36(2) :1-12. http://doi.org/10.4102/ve.v36i2.147

46. Berghs M. Practices and discourses of ubuntu: Implications for an African model of disability? Afr J Disabil 2017;6(1):1-8. https://doi.org/10.4102/ajod.v6.292

47. Bewaji JAI, Ramose MB. The Bewaji, van Binsbergen and Ramose debate on ubuntu. S Afr J Philos 2003;22(4):378-415. http://doi.org/10.4314/sajpem.v22i4.31380

48. Binsbergen WV. Ubuntu and the globalisation of Southern African thought and society. Quest 2001;15(1-2):53-89.

49. Bohler-Muller N. Beyond legal metanarratives: The interrelationship between storytelling, ubuntu and care. Stellenbosch Law Rev 2007;18(1):133-160.

50. Brock-Utne B. The ubuntu paradigm in curriculum work, language of instruction and assessment. Internat Rev Education/Internationale Zeitschrift für Erziehungswissenschaft 2016;62(1):29-44. https://doi.org/10.1007/s11159-0169540-2

51. Eze M. What is African communitarianism? Against consensus as a regulative ideal. S AfrJ Philos 2008;27(4):386-299. https://doi.org/ 10.4314/sajpem.v27i4.31526

52. Farland D. 'African intuitions' and moral theory. S Afr J Philos 2007;26(4):356-363. http://doi.org/10.4314/sajpem.v26i4.31493

53. Gade C. Restorative justice and the South African Truth and Reconciliation process S Afr J Philos 2013;32(1):10-35. https://doi.org/10.1080/02580136.2013.810412

54. Gichure C. Human nature/identity: The ubuntu world view and beyond. In: Coetzee PH, Roux APJ, eds. Philosophy from Africa: A Text with Readings. Oxford: Oxford University Press, 2002

55. Lutz DW. African 'ubuntu' philosophy and global management. J Bus Ethic 2009;84(3):313-328. https://doi.org/10.1007/s10551-009-0204-z

56. Mnyaka M, Motlhabi M. The African concept of ubuntu/botho and its sociomoral significance. Black Theol 2005;3(2):215-237. http://doi.org/10.1558/ blth.3.2.215.65725

57. Tschaepe M. A Humanist ethic of ubuntu: Understanding moral obligation and community. Essays Philos Humanism 2013;21(2):47-61. http://doi.org/10.1558/ eph.v21i2.47

58. Ulvestad A. Ubuntu in African traditional religion. Oslo: University of Oslo, 2012.

59. Metz T. African moral theory and public governance: Nepotism, preferential hiring and other partiality. In: MF Murove (ed.). African Ethics: An Anthology for Comparative and Applied Ethics. Durban: UKZN Press, 2009:335-356.

60. Metz T. Climate change in Africa and the Middle East in light of health, ubuntu and Islam. S Afr J Bioethics Law 2016;9(2):88-92. http://doi.org/10.7196\%2FSAJBL.2016. v9i2.489

61. Metz T. Ethics in Aristotle and in Africa: Some points of contrast. Phronimon 2012;13(2):99-117.

62. Metz T. Replacing development: An Afro-communal approach to global justice. Philosophic Papers 2017;46(1):111-137. https://doi.org/10.1080/05568641.2017.1 295627

63. Mabovula N. The erosion of African communal values: A reappraisal of the African ubuntu philosophy. Inkanyiso J Humanities Soc Sci 2011;3(1):38-47.

64. Plooy BD. Ubuntu and the recent phenomenon of the Charter for Compassion. S Afr Rev Sociol 2014;45(1):83-100. https://doi.org/10.1080/21528586.2014.887916

65. Dreyer JS. Ubuntu. Internat J Practical Theol 2015;19(1):189-209. https://doi. org/10.1515/ijpt-2015-0022

66. Waghid $Y$, Smeyers P. Reconsidering ubuntu: On the educational potential of a particular ethic of care. Educat Philos Theory 2012;44(s2):6-20.

67. Muwanga-Zake J. Building bridges across knowledge systems: Ubuntu and participative research paradigms in Bantu communities. Discourse 2009;30(4):413-426. http://doi.org/10.1080/01596300903237198

68. Forster D. A generous ontology: Identity as a process of intersubjective discovery an African theological contribution. HTS Theological Stud 2010;66(1):1-12. https:// doi.org/10.4102/hts.v66i1.731

69. Bell DA, Metz T. Confucianism and ubuntu: Reflections on a dialogue between Chinese and African traditions. J Chin Philos 2011;38(Suppl):S78-S95.

70. Le Grange L. Ubuntu, ukama, environment and moral education. J Moral Educ 2012;41(3):329-340.

71. Makgoro Y. Ubuntu and the law in South Africa. Potchefstroom Electron Law J 2009;1(1):1-11. https://doi.org/10.4314/pelj.v1i1.43567

72. Shanyanana R, Waghid Y. Reconceptualizing ubuntu as inclusion in African higher education: Towards equalization of voice. Knowledge Cult 2016;4(4):104-20.

73. Metz T. Ubuntu: The good life. In: Michalos AC, ed. Encyclopedia of Quality of Life and Well-Being Research. Dordrecht: Springer Netherlands, 2014:6761-6765.

74. Nussbaum B. Ubuntu: Reflections of a South African on our common humanity Reflections 2003:4(4):21-6.

75. Metz T. Ubuntu as a moral theory and human rights in South Africa. Afr Hum Rights Law J 2011;11(2):532-559.

76. Murove MF. Ubuntu. Diogenes 2012;59(3-4):36-47.

77. Le Grange L. Ubuntu, ukama, environment and moral education. J Moral Educ 2012;41(3):329-340. http://doi.org/10.1080/03057240.2012.691631 
78. Venter E. The notion of ubuntu and communalism in African educational discourse. Stud Philos Educ 2004;23(2/3):149-160.

79. Breed G, Semenya K. Ubuntu, koinonia and diakonia, a way to reconciliation in South Africa? HTS Theol Stud 2015;71(2):1-9.

80. Dolamo R. Botho/ubuntu: The heart of African ethics. Scriptura 2014;112(2013):1 10. https://doi.org/ 10.7833/112-0-781-10

81. Metz T. Recent work in African ethics. J Moral Educ 2010;39(3):381-389.

82. Metz T. A bioethic of communion: Beyond care and the four principles with regard to reproduction. In: Soniewicka M, ed. The Ethics of Reproductive Genetics Between Utility, Principles and Virtues. New York, NY: Springer International Publishing AG, 2017

83. Metz T. Recent philosophies of social protection: From capability to ubuntu. Glob Soc Pol 2016;16(2):132-150.

84. Koenane M, Olatunji C. Is it the end or just the beginning of ubuntu? Response to Matolino and Kwindingwi in view of Metz's rebuttal. S Afr J Philos 2017:36(2):263277. http://doi.org/10.1080/02580136.2016.1225188

85. Kubow P, Min M. The cultural contours of democracy: Indigenous epistemologies informing South African citizenship. Democr Educ 2016;24(2):1-12.

86. Matolino B, Kwindingwi W. The end of ubuntu. S Afr J Philos 2013;32(2):197-205

87. Chasi $C$, Rodny-Gumede $Y$. Ubuntu journalism and nation-building magic. Crit Arts 2016;30(5):728-744. https://doi.org/10.1080/02560046.2016.1262441

88. Metz T. The Western ethic of care or an afro-communitarian ethic? Finding the right relational morality. J Glob Ethics 2013;9(1):77-92.

89. Wareham CS. Partiality and distributive justice in African bioethics. Theor Med Bioeth 2017;38(2):127-44. https://doi.org/10.1007/s11017-017-9401-4

90. Metz T, Gaie JBR. The African ethic ofubuntu/botho: Implications for research on morality. JMoral Educ 2010;39(3):273-290. https://doi.org/10.1080/03057240.20 10.497609

91. Prinsloo ED. A comparison between medicine from an African (ubuntu) and Western philosophy. Curationis 2001;24(1):58-65. https://doi.org/10.4102/ curationis.v24i1.802

92. Chisale S. Love, discipline, punishment or wife battering: A view from ubuntu Gender Behav 2016;14(2):7275-83.

93. Nyaumwe $L J$, Mkabela $Q$. Revisiting the traditional African cultural framework of ubuntuism: A theoretical perspective. Indilinga 2007;6(2):152-163

94. Metz T. An African theory of moral status: A relational alternative to individualism and holism. Ethical Theory Moral Pract 2012;15(3):387-402.

95. Hallen B. Personhood in a communitarian context. Thought Pract J Philos Ass Kenya 2015;7(2):1-10

96. Masowa A, Mamvura Z. African philosophy of development as expressed in Shon proverbs. AFRREV IJAH 2017;6(2):28-40. http://doi.org/10.4314/ijah.v6i2.3

97. Metz T. African ethics and journalism ethics: News and opinion in light of ubuntu. Mass Media Ethics 2015;30(2):74-90.

98. Metz T. An ubuntu-based evaluation of the South African state's responses to Marikana: Where's the reconciliation? Politikon 2017:44(2):287-303.

99. Wyk BV. An analysis of transformation at three South African universities. Educ Change 2004;8(1):164-186.

100. MetzT. Human dignity, capital punishment, and an African moral theory: Toward a new philosophy of human rights. J Hum Rights 2010;9(1):81-99.

101. Mboti N. May the real ubuntu please stand up? J Media Ethics 2015;30(2):125-147. https://doi.org/10.1080/23736992.2015.1020380
102. McCluskey G, Lephalala M. 'A person is a person because of others': Challenges to meanings of discipline in South African and UK schools. Power Educ 2010;2(1):18-30.

103. Metz T. Making sense of survivor's guilt: How to justify it with an African ethic In: Ntsebeza L, Hull G, eds. Philosophy in Africa, Africa in Philosophy. Abingdon: Routledge, 2016.

104. Metz T. African values and human rights as two sides of the same coin: Reply to Oyowe. Afr Hum Rights Law J 2014;14(2):306-321

105. Ngwa W, Ngoma T, Zietman A, et al. Closing the cancer divide through ubuntu: Information and communication technology-powered models for global radiation oncology. Int J Radiat Oncol Biol Phys 2016;94(3):440-449. https://doi. org/10.1016/j.ijrobp.2015.10.063

106. Letseka M. Educating for ubuntu/botho: Lessons from Basotho indigenous education. Open J Philos 2013;3(2):337-344

107. Metz T. Just the beginning for ubuntu: Reply to Matolino and Kwindingwi. S Afr J Philos 2014;33(1):65-72

108. Metz T. Ubuntu and the value of self-expression in the mass media. Communicatio 2015:41(3):388-403.

109. Metz T. Ancillary care obligations in light of an African bioethic: From entrustment to communion. Theor Med Bioeth 2017;38(2):111-126. https://doi.org/10.1007/ s11017-017-9404-1

110. Van Niekerk J. In defence of an autocentric account of ubuntu. S Afr J Philos 2007;26(4):364-368.

111. Behrens KG. A critique of the principle of 'respect for autonomy', grounded in African thought. Develop World Bioeth 2017;17(2):126-134. https://doi. org/10.1111/dewb.12145

112. Ramose MB. The philosophy of ubuntu as a philosophy. In: Coetzee PH, Roux APJ eds. Philosophy From Africa: A Text with Readings. Oxford: Oxford University Press, 2002.

113. Wiredu K. Cultural universals and particulars: An African perspective. Bloomington Indiana University Press, 1996.

114. Ntibagirirwa S. Ubuntu as a metaphysical concept. JValue Inq 2018;52(1):113-133. https://doi.org/10.1007/s10790-017-9605-x

115. Kipnis K. A defense of unqualified medical confidentiality. A J Bioeth 2006;6(2):718. https://doi.org/10.1080/15265160500506308

116. Agyapong Vl, Kirrane R, Bangaru R. Medical confidentiality versus disclosure: Ethical and legal dilemmas. J Forensic Legal Med. 2009;16(2):93-96. https://doi. org/10.1016/j.jlm.2008.08.007

117. Lohiya S. Domestic violence dilemma in the dental clinic. J Am Coll Dentists 2013;80(3):9-11.

118. Bhore SJ. Global goals and global sustainability. Int J Environ Res Pub Health 2016;13(10):1-2. https://doi.org/10.3390/ijerph13100991

119. Sokol DK. Truth-telling in the doctor-patient relationship: A case analysis. Clin Ethics 2006;1(3):1-5.

120. Wright L, MacRae S, Gordon D, et al. Disclosure of misattributed paternity: Issues involved in the discovery of unsought information. Seminars Dialys 2002;15(3):202-206.

Accepted 18 June 2019 